\title{
Composição florística e estrutura fitossociológica de dois fragmentos de floresta de restinga no Município de Bertioga, SP, Brasil ${ }^{1}$
}

\author{
Daniela Guedes ${ }^{2,3,4}$, Luiz Mauro Barbosa ${ }^{3}$ e Suzana Ehlin Martins ${ }^{3}$
}

Recebido em 3/02/2004. Aceito em 12/09/2005

\begin{abstract}
RESUMO - (Composição florística e estrutura fitossociológica de dois fragmentos de floresta de restinga no Município de Bertioga, SP, Brasil). O presente trabalho foi realizado em dois fragmentos de floresta de restinga (floresta inundável e floresta não inundável) no Município de Bertioga, Estado de São Paulo, em uma área com extensão total aproximada de $3.000 .000 \mathrm{~m}^{2}$, pertencente ao condomínio residencial Riviera de São Lourenço. Para o levantamento fitossociológico foram instaladas 48 parcelas de $10 \times 10 \mathrm{~m}$ distribuídas em blocos de 20×30 m e de 10×30 m, onde foram amostrados todos os indivíduos lenhosos com perímetro do caule à altura do peito (PAP) igual ou superior a $10 \mathrm{~cm}$. Foram levantados 893 indivíduos distribuídos em 83 espécies e 31 famílias. As espécies da floresta não inundável com maior valor de importância (VI) foram: Manilkara subsericea (Mart.) Dubard, Amaioua intermedia Mart. ex K. Schum., Didymopanax angustissimum A. Sampaio, Miconia cubatanensis Hoehne, Euterpe edulis Mart., Syagrus pseudococos (Raud.) Glassm., Bactris setosa Mart., Guarea macrophylla Vahl. e Nectandra oppositifolia Ness \& Mart. ex Mez. e na floresta inundável: Eriotheca pentaphylla (Vell. emend K. Schum.) A. Robyns, Calophyllum brasiliense Cambess., Syagrus pseudococos, Tabebuia cassinoides (Lam.) DC., Manilkara subsericea, Tabebuia obtusifolia (Cham) Bureau, Didymopanax angustissimum, Sloanea guianensis (Aubl.) Benth. e Amaioua intermedia. O índice de diversidade de Shannon (H') foi de 3,50 nats/ind. para a floresta inundável e 3,70 nats/ind. para a floresta não inundável.
\end{abstract}

Palavras-chave: Floresta de restinga inundável, Floresta de restinga não inundável, fisionomia, planície litorânea

\begin{abstract}
Floristic and phytosociological analysis of two fragments of restinga forest in Bertioga, São Paulo State, Brazil). A phytosociological investigation in two fragments of restinga forest (flooded and nonflooded) in Riviera de São Lourenço complex, Bertioga, São Paulo, was carried out. Each fragment in the phytosociological survey was studied using $10 \times 10 \mathrm{~m}$ plots. These plots were distributed in blocks of $20 \times 30 \mathrm{~m}$ and $10 \times 30 \mathrm{~m}$, for a total area of $4,800 \mathrm{~m}^{2}$. The 893 individuals sampled in both fragments were distributed in 83 species and 31 families. The species with highest importance values (IV) in the flooded restinga forest were: Manilkara subsericea (Mart.) Dubard, Amaioua intermedia Mart. ex K. Schum., Didymopanax angustissimum A. Sampaio, Miconia cubatanensis Hoehne, Euterpe edulis Mart., Syagrus pseudococos (Raud.) Glassm., Bactris setosa Mart., Guarea macrophylla Vahl. and Nectandra oppositifolia Ness \& Mart. ex Mez; in nonflooded restinga forest these were: Eriotheca pentaphylla (Vell. emend K. Schum.) A. Robyns, Calophyllum brasiliense Cambess., Syagrus pseudococos, Tabebuia cassinoides (Lam.) DC., Manilkara subsericea, Tabebuia obtusifolia (Cham) Bureau, Didymopanax angustissimum, Sloanea guianensis (Aubl.) Benth. and Amaioua intermedia. Shannon's diversity index (H') was 3.50 in the flooded restinga forest and 3.70 in the nonflooded restinga forest.
\end{abstract}

Key words: Flooded restinga forest, unflooded restinga forest, physiognomy, coastal plain

\section{Introdução}

As restingas e dunas de areia que cobrem cerca de $70 \%$ do litoral brasileiro compõem-se de um imenso mosaico de comunidades vegetais, florística e estruturalmente diferentes, que nas regiões Sul e Sudeste é representado por formações herbáceas, arbustivas e florestais cujas diferenças ocorrem, basicamente, em função da proximidade do mar e das características físicas e hidrológicas do substrato (Klein 1961; Araújo 1992).

Dependendo da extensão da planície litorânea, da direção predominante dos cordões arenosos marinhos, e das características físicas, nutricionais e hidrológicas do substrato, com influência de depósito de sedimentos das escarpas ou fluviais, há um arranjo heterogêneo de trechos de florestas que podem variar em relação à altura, à saturação hídrica do solo e distância da

\footnotetext{
1 Parte da Tese de Doutorado da primeira Autora

2 Universidade Estadual Paulista, Rio Claro, SP, Brasil

3 Instituto de Botânica, C. Postal 4005, CEP 01061-970, São Paulo, SP, Brasil

4 Autor para correspondência: danielaguedes1@hotmail.com
} 
encosta atlântica (Klein 1961; Henriques et al. 1986; Silva 1998; Mantovani 2000; Marques 2002).

Dentre as fisionomias florestais localizadas nas planícies costeiras da região Sudeste encontram-se as florestas que ocorrem nas partes mais altas dos cordões litorâneos, em locais bem drenados e com solos arenosos; e as florestas localizadas nas depressões entre cordões onde há afloramento periódico do lençol freático e solos de origem mineral misturados à matéria orgânica em diferentes graus de decomposição (Waechter 1986; Silva \& Britez 2005).

Tais grupos de florestas podem apresentar as mais diversas denominações como mata seca ou mata alta, para as áreas não inundadas e; mata paludosa, mata brejosa, mata alagada, mata inundada ou mata turfosa para as áreas que sofrem alagamento (Araújo \& Henriques 1984; Pereira 1990; Silva 1990; Sugiyama 1998; Conama 1996).

No geral, as florestas de restinga variam desde 4 até $20 \mathrm{~m}$ de altura, dependendo das características do substrato e da influência da salinidade, e podem muitas vezes apresentar um conjunto de espécies em comum. $\mathrm{O}$ aspecto xeromórfico destas florestas é evidenciado por árvores com troncos ramificados e tortuosos, copas ralas deformadas unilateralmente devido à ação abrasiva das partículas de areia e sal levadas pela ação dos ventos, com folhas coriáceas e cerosas (Silva 1990; Silva \& Britez 2005).

Por estarem estabelecidas sobre solos arenosos, altamente lixiviados e pobres em nutrientes, estas formações vegetacionais são muito frágeis e passíveis de perturbações, o que torna a conservação dependente em grande extensão dos mecanismos intrínsecos existentes na sua comunidade vegetal, tais como presença de micorrizas, escleromorfismo e caráter perenifólio dificultando a recuperação das áreas degradadas (Araújo \& Lacerda 1987; Moraes et al. 1999).

Na Baixada Santista, a vegetação de restinga constitui uma faixa que vai da parte posterior das dunas até, praticamente, o sopé da Serra do Mar. Originalmente esta vegetação estendia-se por um território de aproximadamente $413 \mathrm{~km}^{2}$. Em função das condições mais propícias à ocupação e da fragilidade e suscetibilidade a perturbações causadas pelo homem, esse ecossistema foi o que mais perdeu espaço para assentamento de infra-estrutura urbana (Andrade \& Lamberti 1965; Araújo \& Lacerda 1987; Consórcio Mata Atlântica 1992; Silva et al. 1993).

Da totalidade das florestas de restinga originalmente existentes na Baixada Santista restam, com estrutura fisionômica e composição florística preservadas, aproximadamente $22 \%\left(90 \mathrm{~km}^{2}\right)$. Deste total, $88 \mathrm{~km}^{2}$ situam-se em mancha praticamente contínua na porção setentrional da Planície de Bertioga. O restante das florestas de restinga, que corresponde a $323 \mathrm{~km}^{2}$ (78\%), atualmente apresentase alterado por desmatamentos, extração de areia, influência da poluição industrial, sendo que 162 km² são ocupados por estruturas urbanas que ocorreram para fins de lazer e provocaram eliminação da vegetação natural, estímulos a processos erosivos e mudanças nas características de drenagens dos solos, entre outras conseqüências (Silva et al. 1993; Rodrigues 2000).

Em relação à composição florística da restinga, observa-se que as famílias mais importantes entre árvores e arbustos são Myrtaceae, Aquifoliaceae, Clusiaceae e Lauraceae. A maioria está largamente distribuída em outros hábitats, havendo um grande número de espécies da Serra do Mar, que caracteristicamente invadem a vegetação da restinga. Dentre as plantas da mata que se encontram na restinga, incluem-se árvores, arbustos e mesmo as lianas e epífitas tão freqüentes na Mata Pluvial Tropical (Andrade \& Lamberti 1965).

Apesar de sua importância e enorme diversidade, as formações sobre as restingas no Estado de São Paulo são pouco conhecidas em relação a florística e a estrutura fitossociológica, podendo ser citados os trabalhos de De Grande \& Lopes (1981), Barros et al. (1991) e Sugiyama (1998), na Ilha do Cardoso; Ramos Neto (1993) e Carvalhaes (1997), em Iguape; Furlan et al. (1990), Garcia \& Monteiro (1993), Ribeiro \& Monteiro (1993), Romero \& Monteiro (1993), Cesar \& Monteiro (1995) e Assis (1999), em Picinguaba; Mantovani (1992), em Caraguatatuba; Kirizawa et al. (1992), em Ilha Comprida; Sztutman \& Rodrigues (2002), em Pariquera-Açu; e Girardi (2001) e S.E. Martins et al. (dados não publicados), em Bertioga.

Observa-se que em Bertioga há poucos estudos sobre a vegetação de restinga, sendo portanto, de grande importância a realização de pesquisas geradoras de maiores informações sobre este tipo de formação florestal, que vem sofrendo ameaça de degradação devido ao incremento do processo ocupacional (Silva et al. 1993).

Dessa forma, o presente trabalho tem como objetivo descrever a composição florística e a estrutura fitossociológica de dois fragmentos de floresta de restinga localizados no município de Bertioga, SP, que estão sujeitos a diferentes níveis de fertilidade e de regime de água no solo. 


\section{Material e métodos}

Local de estudo - O município de Bertioga (2351'S e $\left.46^{\circ} 08^{\prime} \mathrm{O}\right)$, incluído na segunda região ecológica do Estado de São Paulo - Litoral Norte (Troppmair 1975), localiza-se no limite nordeste da Baixada Santista, em uma área situada à beira do canal marítimo que separa a Ilha de Santo Amaro do continente (Medeiros 1965).

Conforme Köppen (1948), o clima da região de Bertioga é classificado como tipo Af, (tropical com chuvas o ano todo), com médias anuais de temperatura em torno de $24{ }^{\circ} \mathrm{C}$ e pluviosidade de $3.207 \mathrm{~mm}$, com os maiores valores médios ocorrendo em janeiro, fevereiro e março, enquanto os menores em junho e julho, revelando um excedente hídrico em todos os meses do ano.

O local onde foi realizado o trabalho possui $3.000 .000 \mathrm{~m}^{2}$, é de propriedade do condomínio residencial Riviera de São Lourenço, apresenta acesso na altura do km 212 da BR 101; encontra-se cortado pela rodovia e por diversos arruamentos no interior do condomínio, formando um conjunto de fragmentos de diferentes tamanhos e formas sobre os quais desenvolve-se uma vegetação de restinga com diferentes fisionomias; segundo Veloso et al. (1991) é uma formação pioneira com influência marinha, representando um sistema edáfico de primeira ocupação.

O empreendimento imobiliário Riviera de São Lourenço que ocupa toda a Enseada de São Lourenço, trata-se de um gigantesco condomínio implantado em 1986, que provocou uma acentuada transformação na paisagem natural, até então intocada, com abertura de arruamentos e início da construção de prédios. Em 1977 a planície litorânea da enseada era recoberta em toda a sua extensão por vegetação, onde eram facilmente perceptíveis os cordões litorâneos. Atualmente, a vegetação natural vai cedendo lugar a arruamentos e construções, sendo alguns terrenos desmatados e mantidos assim por longo tempo, à espera de valorização imobiliária ou para evitar que alguma lei proíba o desmatamento, o que se destaca como grandes áreas de solos expostos (Fierz \& Rosa 1999).

As áreas de estudo, propriamente ditas, estão representadas por dois fragmentos de floresta de restinga que representam a área do empreendimento destinada à reserva. Tais áreas apresentam formato e tamanhos semelhantes $\left(428.000 \mathrm{~m}^{2} \mathrm{e} 385.000 \mathrm{~m}^{2}\right)$, mas solos com diferentes características, sendo denominadas de área 1 - floresta de restinga inundável e área 2 - floresta de restinga não inundável.
A área 1 apresenta árvores altas, com indivíduos emergentes de até mais de $20 \mathrm{~m}$, epifitismo bem desenvolvido com predomínio de bromélias de grande porte, sub-bosque formado por espécies jovens do estrato arbóreo com predomínio de Myrtaceae, e pequena diversidade e quantidade de trepadeiras. $\mathrm{O}$ substrato apresenta uma trama de raízes superficiais, com grande quantidade de material orgânico e presença de restos vegetais semi-decompostos (Ramos-Neto 1993; Conama 1996). Esta área localiza-se nas depressões entre os cordões litorâneos, e possui lençol freático bastante superficial podendo aflorar nas épocas mais úmidas do ano, que no período de estudo (2000 a 2002) foram representadas pelos meses de dezembro, janeiro, fevereiro e março.

A área 2 é também representada por uma formação florestal de estrato predominantemente arbóreo, com alturas superiores a $20 \mathrm{~m}$. Apresenta alta diversidade de epífitas e significativa quantidade de trepadeiras. Esta floresta ocorre em solos de origem marinha, nas partes altas dos cordões litorâneos, não ficando sujeita a alagamentos prolongados. Neste local, o solo apresenta-se seco, arenoso e com uma camada de material orgânico superficial, que esconde uma fina trama de raízes (Sugiyama 1998; Conama 1996)

Coleta de dados de solo - O solo foi caracterizado por meio da análise química e textural de cinco amostras simples, nas profundidades de 0 a $15 \mathrm{~cm}$ e de 15 a $30 \mathrm{~cm}$, em cada uma das áreas de estudo. As coletas foram reunidas em uma amostra composta, para cada profundidade e para cada área, embaladas em caixas de papelão e enviadas para o Instituto Agronômico de Campinas. A metodologia empregada para a análise química foi a de Raij \& Quaggio (1983) e para a análise textural a de Raij \& Zullo (1977).

Coleta de dados da vegetação - Para análise da estrutura fitossociológica da vegetação utilizou-se 48 parcelas de $10 \times 10 \mathrm{~m}$ distribuídas em cada fragmento.

No primeiro fragmento (área 1) foram instaladas quatro unidades amostrais, constando de quatro blocos de $20 \times 30 \mathrm{~m}$, no segundo fragmento (área 2) foram locados três blocos de $20 \times 30 \mathrm{~m}$ e dois blocos de $10 \times 30 \mathrm{~m}$, totalizando $2.400 \mathrm{~m}^{2} \mathrm{em}$ cada área.

As parcelas foram delimitadas com estacas de alumínio e barbante. Em cada parcela considerou-se todos os indivíduos com perímetro do caule à altura do peito (PAP) igual ou superior a $10 \mathrm{~cm}$.

Cada um dos indivíduos amostrados foi numerado com uma plaqueta de alumínio, tendo seu perímetro medido com fita métrica a $1,30 \mathrm{~m}$ do solo e a sua altura 
estimada visualmente. Nos indivíduos ramificados, quando pelo menos um dos caules possuía o critério adotado, media-se o perímetro de todas as ramificações.

A coleta do material botânico foi realizada com o auxílio de uma tesoura de poda alta acoplada a uma vara de coleta composta por vários segmentos, que atingem cerca de $20 \mathrm{~m}$ de altura. Para as árvores mais altas foi necessário o trabalho de um mateiro que, com auxílio de esporas, escalou-as até alcançar a copa e realizar as coletas.

As amostras foram numeradas com fita adesiva e acondicionadas em sacos plásticos, de onde foram retiradas, prensadas e herborizadas.

As exsicatas foram identificadas com o auxílio de especialistas, bibliografia especializada e consultas para comparação com materiais depositados em herbários no Estado de São Paulo.

A partir dos dados obtidos no campo, foram calculados para cada um dos fragmentos estudados, os valores de importância, frequiências, densidades e dominâncias relativas para cada espécie (MüllerDombois \& Ellenberg 1974) e o índice de diversidade de Shannon \& Weaner (H') da comunidade (Pielou 1975), utilizando o programa Fitopac-2 (Shepherd 1994). Os valores de H' obtidos para as duas áreas foram comparados pelo teste $t$ de Hutcheson (Zar 1996).

Para a análise da similaridade florística, foram realizadas comparações entre as áreas de estudo e outras áreas de floresta de restinga no Estado de São Paulo utilizando-se o índice de Jaccard (Magurran 1988).

\section{Resultados}

Apesar do solo na área 1 ter sido coletado, não foi possível a realização da sua análise granulométrica, visto que a amostra era constituída exclusivamente por matéria orgânica. A área 2, por sua vez, apresenta dominância da fração areia nas duas profundidades (cerca de 95\%), com teores de silte e argila muito baixos (Tab. 1).

Tabela 1. Análise granulométrica do solo da área 2 (floresta de restinga não inundável). Município de Bertioga, SP, Brasil.

\begin{tabular}{ccccc}
\hline $\begin{array}{c}\text { Prof. } \\
(\mathrm{cm})\end{array}$ & $\begin{array}{c}\text { Argila } \\
(\%)\end{array}$ & $\begin{array}{c}\text { Silte } \\
(\%)\end{array}$ & $\begin{array}{c}\text { Areia total } \\
(\%)\end{array}$ & $\begin{array}{c}\text { Classificação } \\
\text { textural }\end{array}$ \\
\hline $0-15$ & 2,52 & 1,29 & 94,18 & Areia \\
$15-30$ & 3,90 & 0,01 & 96,09 & Areia \\
\hline
\end{tabular}

De uma forma geral, devido ao elevado teor de matéria orgânica humificada, a área 1 apresenta teores de nutrientes significativamente superiores aos da área 2 (Tab. 2), associado a isto, a área 1 ainda apresenta afloramento do lençol freático, expondo a vegetação a um constante encharcamento do solo.

O levantamento florístico realizado durante o período de estudo revelou a presença de 31 famílias e 81 espécies (65 na área 1 e 67 na área 2) (Tab. 3).

$\mathrm{Na}$ área 1 as famílias com maior riqueza de espécies foram Myrtaceae, com 15 espécies $(23,43 \%)$, Lauraceae (6 espécies; 9,37\%), Rubiaceae (cinco; 7,81\%), Arecaceae (quatro; 6,25\%) e Bignoniaceae e Melastomataceae (três cada; $4,68 \%$ ). E na área 2 Myrtaceae, com 18 espécies (26,86\%), foi também a família melhor representada, seguida de Lauraceae (8 espécies; 11,94\%), Arecaceae (quatro; $5,97 \%$ ) e Bignoniaceae e Rubiaceae (três cada; $4,47 \%)$.

Por meio da fórmula proposta por Jaccard comparou-se as espécies presentes ou ausentes entre a área 1 e a área 2 deste estudo, e entre estas e outras áreas de floresta de restinga do Estado de São Paulo. Conforme a Tab. 4 as áreas 1 e 2 apresentam índice de Jaccard igual a $63 \%$ com 52 espécies em comum. Em relação a outras áreas observa-se que as maiores similaridades ocorrem entre área 1 e Bertioga (restinga paludosa) e área 2 e Bertioga (restinga paludosa).

Nas 48 parcelas (24 em cada área) foram amostrados 893 indivíduos arbóreos, sendo 476 na área 1 e 417 na área 2, conferindo-lhes densidades totais de 1983,3 ind./ha e 1737,5 ind./ha, respectivamente para cada área, e áreas basais totais de $26,64 \mathrm{~m}^{2} / \mathrm{ha}$ (área 1) e 27,69 m²/ha (área 2).

$\mathrm{Na}$ área 1 as espécies com maior número de indivíduos foram: Amaioua intermedia, com 17,0\% do total, Syagrus pseudococos (6,5\%), Didymopanax angustissimum (6,3\%), e Manilkara subsericea $(5,7 \%)$. Na área 2 as espécies mais abundantes foram: Tabebuia cassinoides (7,4\%), Syagrus pseudococos $(6,7 \%)$, Eriotheca pentaphylla $(6,2 \%)$, e Tabebuia obtusifolia (5,5\%) (Tab. 5, 6).

Os índices de diversidade de Shannon (H') encontrados para as duas áreas de floresta de restinga estudadas foram de 3,50 nats/ind. (área 1) e 3,70 nats/ind. (área 2), enquanto os valores de equiabilidade (J) obtidos foram de 0,838 e 0,880 , respectivamente para as duas áreas. A comparação feita pelo do teste de $t$ de Hutcheson $(\mathrm{P}<0,05)$, mostra que os índices de diversidade das duas áreas são estatisticamente diferentes. 


\section{Discussão}

De acordo com IPT (1981), o caráter orgânico do solo da área 1 deve-se ao acúmulo de material vegetal relacionado ao preenchimento de lagoas ou de meandros de rios abandonados, que em função do ambiente anóxico associado ao afloramento periódico do lençol freático, permanece apenas parcialmente decomposto.

Já na área 2, localizada nas partes altas dos cordões litorâneos e, portanto, com solo formado por depósitos de origem marinha e eólica, apresenta drenagem rápida, com pequena retenção de água e elevada lixiviação, devido à sua textura (Ramos-Neto 1993; Silva \& Britez 2005).

$\mathrm{O}$ baixo $\mathrm{pH}$ da área 1 limita a presença de organismos decompositores, reduzindo a decomposição do material vegetal (Mohr \& Van Baren 1959), principalmente quando associado a excesso de umidade. Por ser uma fonte de nutrientes, a matéria orgânica libera-os gradualmente para as plantas, retendo grande parte em forma de quelatos e diminuindo a lixiviação destes para fora da zona das raízes (Moraes et al. 1999).

$\mathrm{Na}$ área 2 a atividade dos organismos decompositores heterotróficos deve ocorrer em uma velocidade maior do que na área 1, fazendo com que os nutrientes sejam liberados mais rapidamente e, desta forma, perdendo-se por lixiviação ou volatilização (Jordan 1985); por isso esta área apresenta solo com valores muito baixos para todos os nutrientes, com exceção dos micronutrientes.

A elevada acidez do solo, principalmente na área 1, além de interferir na disponibilidade de nutrientes, favorece o aparecimento de alumínio trocável em solução, o que causa toxidez, tornando as raízes curtas e com baixa eficiência. Com a falta de cálcio e o excesso de alumínio, o sistema radicular desenvolve-se superficialmente, resultando na exploração de um menor volume de solo, e portanto, menor absorção de água e nutrientes (Casagrande 2003).

Não obstante os solos tenham apenas cerca de 3 a 4\% de argila, as CTCs são elevadas, notadamente na área 1, devido ao elevado teor de matéria orgânica. A despeito disso, a saturação por bases (V\%), que representa a porcentagem de $\mathrm{K}+\mathrm{Ca}+\mathrm{Mg}$ em relação a CTC, é muito baixa, menor que 5\% para as duas áreas. Isto significa que os dois solos são limitantes quanto à fertilidade para o desenvolvimento vegetal, estando a CTC ocupada principalmente por hidrogênio e alumínio, cuja a porcentagem de saturação é vista 
Tabela 3. Espécies ocorrentes na área 1 (floresta de restinga inundável) e na área 2 (floresta de restinga não inundável), Município de Bertioga, SP, Brasil.

\begin{tabular}{|c|c|c|}
\hline Famílias/Espécies & Área 1 & Área 2 \\
\hline \multicolumn{3}{|l|}{ ANACARDIACEAE } \\
\hline Tapirira guianensis Aubl. & $\mathrm{X}$ & $\mathrm{X}$ \\
\hline \multicolumn{3}{|l|}{ ANNONACEAE } \\
\hline Guatteria hillariana Schlecht. & $\mathrm{X}$ & $\mathrm{X}$ \\
\hline \multicolumn{3}{|l|}{ AQUIFOLIACEAE } \\
\hline Ilex theezans Mart. & $\mathrm{X}$ & $\mathrm{X}$ \\
\hline I. amara (Vell.) Loes. & $\mathrm{X}$ & - \\
\hline \multicolumn{3}{|l|}{ ARALIACEAE } \\
\hline Didymopanax angustissimum A. Sampaio & $\mathrm{X}$ & $\mathrm{X}$ \\
\hline \multicolumn{3}{|l|}{ ARECACEAE } \\
\hline Astrocaryum aculeatissimum (Schott.) Burret. & $\mathrm{X}$ & $\mathrm{X}$ \\
\hline Bactris setosa Mart. & $\mathrm{X}$ & $\mathrm{X}$ \\
\hline Euterpe edulis Mart. & $\mathrm{X}$ & $\mathrm{X}$ \\
\hline Syagrus pseudococos (Raud.) Glassm. & $\mathrm{X}$ & $\mathrm{X}$ \\
\hline \multicolumn{3}{|l|}{ BIGNONIACEAE } \\
\hline Jacaranda puberula Cham. & $\mathrm{X}$ & $\mathrm{X}$ \\
\hline Tabebuia cassinoides (Lam.) DC. & $\mathrm{X}$ & $\mathrm{X}$ \\
\hline T. obtusifolia (Cham) Bureau & $\mathrm{X}$ & $\mathrm{X}$ \\
\hline \multicolumn{3}{|l|}{ BOMBACACEAE } \\
\hline $\begin{array}{l}\text { Eriotheca pentaphylla (Vell. emend } \\
\text { K. Schum.) A. Robyns }\end{array}$ & - & $\mathrm{X}$ \\
\hline \multicolumn{3}{|l|}{ BORAGINACEAE } \\
\hline Cordia sellowiana Cham. & - & $\mathrm{X}$ \\
\hline \multicolumn{3}{|l|}{ CECROPIACEAE } \\
\hline Cecropia glaziovii Snethl. & - & $\mathrm{X}$ \\
\hline Coussapoa microcarpa (Schott) Rizzini & - & $\mathrm{X}$ \\
\hline \multicolumn{3}{|l|}{ CELASTRACEAE } \\
\hline Maytenus robusta Reiss. & $\mathrm{X}$ & $\mathrm{X}$ \\
\hline \multicolumn{3}{|l|}{ CHLORANTHACEAE } \\
\hline Hedyosmum brasiliense Mart. ex Miq. & - & $\mathrm{X}$ \\
\hline \multicolumn{3}{|l|}{ CLUSIACEAE } \\
\hline Calophyllum brasiliense Cambess. & $\mathrm{X}$ & $\mathrm{X}$ \\
\hline Garcinia gardneriana (Planch. \& Triana) Zappi & i $X$ & $\mathrm{X}$ \\
\hline \multicolumn{3}{|l|}{ CYATHEACEAE } \\
\hline Trichipteris atrovirens (Langsd. \& Fisch) Tryon & $X$ & $\mathrm{X}$ \\
\hline \multicolumn{3}{|l|}{ ELAEOCARPACEAE } \\
\hline Sloanea guianensis (Aubl.) Benth. & $\mathrm{X}$ & $\mathrm{X}$ \\
\hline \multicolumn{3}{|l|}{ EUPHORBIACEAE } \\
\hline Alchornea triplinervia (Spreng.) M. Arg. & $\mathrm{X}$ & $\mathrm{X}$ \\
\hline Pera glabrata (Schott) Baill. & $\mathrm{X}$ & $\mathrm{X}$ \\
\hline \multicolumn{3}{|l|}{ FABACEAE } \\
\hline Andira fraxinifolia Benth. & $\mathrm{X}$ & $\mathrm{X}$ \\
\hline Dahlstedtia pinnata (Benth.) Malme. & $\mathrm{X}$ & - \\
\hline \multicolumn{3}{|l|}{ LAURACEAE } \\
\hline Aniba firmula (Nees \& Mart.) Mez & - & $\mathrm{X}$ \\
\hline Endlicheria paniculata (Spreng.) Macbr. & $\mathrm{X}$ & $\mathrm{X}$ \\
\hline Nectandra oppositifolia Ness \& Mart. ex Mez & $\mathrm{X}$ & $\mathrm{X}$ \\
\hline Nectandra sp. & $\mathrm{X}$ & $\mathrm{X}$ \\
\hline Ocotea aciphylla (Nees) Mez & - & $\mathrm{X}$ \\
\hline O. lobbii (Meisn.) Mez & $\mathrm{X}$ & $\mathrm{X}$ \\
\hline O. pulchella (Nees) Mez & - & $\mathrm{X}$ \\
\hline O. venulosa (Nees) Baitello & - & $\mathrm{X}$ \\
\hline Ocotea sp. & $\mathrm{X}$ & $\mathrm{X}$ \\
\hline \multicolumn{3}{|l|}{ MELASTOMATACEAE } \\
\hline Miconia cubatanensis Hoehne & $\mathrm{X}$ & $X$ \\
\hline M. fasciculata Gardner & $\mathrm{X}$ & - \\
\hline M. sellowiana Naudin & $\mathrm{X}$ & - \\
\hline
\end{tabular}

\begin{tabular}{|c|c|c|}
\hline Famílias/Espécies & Área 1 & Área 2 \\
\hline \multicolumn{3}{|l|}{ MELIACEAE } \\
\hline Cabralea canjerana (Vell.) Mart. & $\mathrm{X}$ & $\mathrm{X}$ \\
\hline Guarea macrophylla Vahl. & $\mathrm{X}$ & $\mathrm{X}$ \\
\hline \multicolumn{3}{|l|}{ MIMOSACEAE } \\
\hline $\begin{array}{l}\text { Abarema brachystachya (Candolle) } \\
\text { Barneby \& Grimes }\end{array}$ & $X$ & - \\
\hline Balizia pedicellaris (DC.) Barneby \& Grimes & - & $\mathrm{X}$ \\
\hline Inga edulis Mart. & - & $\mathrm{X}$ \\
\hline \multicolumn{3}{|l|}{ MONIMIACEAE } \\
\hline Mollinedia oligantha Perkins & $\mathrm{X}$ & - \\
\hline M. schottiana (Spreng.) Perkins & $\mathrm{X}$ & - \\
\hline \multicolumn{3}{|l|}{ MORACEAE } \\
\hline Ficus luschnatiana (Miq.) Miq. & $X$ & - \\
\hline \multicolumn{3}{|l|}{ MYRSINACEAE } \\
\hline Cybianthus peruvianus (A. DC.) Miq. & $X$ & $\mathrm{X}$ \\
\hline Rapanea venosa (A. DC.) Mez & $\mathrm{X}$ & $\mathrm{X}$ \\
\hline \multicolumn{3}{|l|}{ MYRTACEAE } \\
\hline Calyptranthes concinna DC. & - & $\mathrm{X}$ \\
\hline Eugenia handroana D. Legrand & - & $\mathrm{X}$ \\
\hline E. monosperma Vell. & $\mathrm{X}$ & $\mathrm{X}$ \\
\hline E. neolanceolata Sobral & $\mathrm{X}$ & $\mathrm{X}$ \\
\hline E. oblongata $\mathrm{O}$. Berg. & $X$ & $\mathrm{X}$ \\
\hline E. cf. riedeliana O. Berg. & $\mathrm{X}$ & $\mathrm{X}$ \\
\hline E. stigmatosa DC. & $\mathrm{X}$ & $\mathrm{X}$ \\
\hline E. sulcata Spring ex Mart. & $\mathrm{X}$ & $\mathrm{X}$ \\
\hline E. umbelliflora O. Berg. & $\mathrm{X}$ & $\mathrm{X}$ \\
\hline Eugenia sp.1 & $\mathrm{X}$ & $\mathrm{X}$ \\
\hline Eugenia sp.2 & - & $\mathrm{X}$ \\
\hline Marlierea racemosa (Vell.) Kiaersk. & $\mathrm{X}$ & - \\
\hline M. tomentosa Cambess. & - & $\mathrm{X}$ \\
\hline Myrcia acuminatissima $\mathrm{O}$. Berg. & $X$ & $\mathrm{X}$ \\
\hline M. cf. brasiliensis Kiaersk. & - & $\mathrm{X}$ \\
\hline M. fallax (Rich.) DC. & $\mathrm{X}$ & $\mathrm{X}$ \\
\hline M. grandiflora (Berg) Legr. & $\mathrm{X}$ & $\mathrm{X}$ \\
\hline M. multiflora (Lam.) DC. & $\mathrm{X}$ & $\mathrm{X}$ \\
\hline Myrcia sp. & $\mathrm{X}$ & - \\
\hline Myrtaceae sp.1 & $\mathrm{X}$ & $\mathrm{X}$ \\
\hline Myrtaceae sp.2 & $\mathrm{X}$ & $\mathrm{X}$ \\
\hline \multicolumn{3}{|l|}{ NYCTAGINACEAE } \\
\hline Guapira opposita (Vell) Reitz. & $\mathrm{X}$ & $\mathrm{X}$ \\
\hline \multicolumn{3}{|l|}{ OLACACEAE } \\
\hline Heisteria silvianii Schwacke & $\mathrm{X}$ & $\mathrm{X}$ \\
\hline \multicolumn{3}{|l|}{ PODOCARPACEAE } \\
\hline Podocarpus sellowii Klotzsch & $\mathrm{X}$ & - \\
\hline \multicolumn{3}{|l|}{ RUBIACEAE } \\
\hline Amaioua intermedia Mart. ex K. Schum. & $\mathrm{X}$ & $\mathrm{X}$ \\
\hline Psychotria carthagenensis Jacq. & $\mathrm{X}$ & $\mathrm{X}$ \\
\hline P. deflexa DC. & $\mathrm{X}$ & - \\
\hline Posoqueria latifolia Roem \& Shiult. & $\mathrm{X}$ & - \\
\hline Rudgea coriacea (Spreng) Shumann & $\mathrm{X}$ & $\mathrm{X}$ \\
\hline \multicolumn{3}{|l|}{ SAPINDACEAE } \\
\hline Cupania oblongifolia Camb. & - & $\mathrm{X}$ \\
\hline Matayba junglandifolia (Camb.) Radlk. & $X$ & $\mathrm{X}$ \\
\hline \multicolumn{3}{|l|}{ SAPOTACEAE } \\
\hline Manilkara subsericea (Mart.) Dubard & $\mathrm{X}$ & $\mathrm{X}$ \\
\hline \multicolumn{3}{|l|}{ THEACEAE } \\
\hline Gordonia fruticosa (Schrad.) H. Keng. & $\mathrm{X}$ & $\mathrm{X}$ \\
\hline
\end{tabular}


Tabela 4. Similaridade florística entre as áreas de estudo (área 1: floresta de restinga inundável e área 2: floresta de restinga não inundável) no município de Bertioga, SP, Brasil e outras áreas de floresta de restinga no Estado de São Paulo, Brasil.

\begin{tabular}{|c|c|c|c|c|}
\hline $\begin{array}{c}\text { Área } 1 \\
\text { (Similaridade) }\end{array}$ & $\begin{array}{c}\text { Área } 2 \\
\text { (Similaridade) }\end{array}$ & Outros trechos & Autores & Síntese da metodologia \\
\hline $13,0 \%$ & $12,8 \%$ & $\begin{array}{l}\text { Ilha do Cardoso } \\
\text { (restinga baixa) }\end{array}$ & Sugiyama (1998) & $\begin{array}{l}\text { Método de parcelas; PAP } \\
\geq 5 \mathrm{~cm} \text {; área amostral: } 0,1 \text { ha }\end{array}$ \\
\hline $30,6 \%$ & $28,7 \%$ & $\begin{array}{l}\text { Ilha do Cardoso } \\
\text { (restinga alta) }\end{array}$ & Sugiyama (1998) & $\begin{array}{l}\text { Método de parcelas; PAP } \geq \\
8 \mathrm{~cm} \text {; área amostral: } 0,27 \text { ha }\end{array}$ \\
\hline $24,1 \%$ & $25,3 \%$ & Pariquera-Açu & Sztutman \& Rodrigues (2002) & $\begin{array}{l}\text { Método de parcelas; PAP } \\
\geq 15 \mathrm{~cm} \text {; área amostral: } 0,5 \text { ha }\end{array}$ \\
\hline $19,3 \%$ & $21,2 \%$ & $\begin{array}{c}\text { Juréia } \\
\text { (restinga baixa) }\end{array}$ & Carvalhaes (1997) & $\begin{array}{l}\text { Método de parcelas; PAP } \\
\geq 15 \mathrm{~cm} \text {; área amostral: } 0,1 \text { ha }\end{array}$ \\
\hline $15,8 \%$ & $17,4 \%$ & $\begin{array}{c}\text { Iguape } \\
\text { (restinga seca) }\end{array}$ & Ramos Neto (1993) & $\begin{array}{l}\text { Método de parcelas; PAP } \\
\geq 20 \mathrm{~cm} \text {; área amostral: } 0,15 \text { ha }\end{array}$ \\
\hline $16,7 \%$ & $16,5 \%$ & $\begin{array}{c}\text { Iguape } \\
\text { (restinga paludosa) }\end{array}$ & Ramos Neto (1993) & $\begin{array}{l}\text { Método de parcelas; PAP } \\
\geq 20 \mathrm{~cm} \text {; área amostral: } 0,15 \text { ha }\end{array}$ \\
\hline $37,6 \%$ & $37,3 \%$ & $\begin{array}{c}\text { Bertioga } \\
\text { (restinga paludosa) }\end{array}$ & $\begin{array}{c}\text { S.E. Martins et al. } \\
\text { (dados não publicados) }\end{array}$ & $\begin{array}{l}\text { Método de parcelas; altura } \\
\text { acima de } 2 \mathrm{~m} \text {; área amostral: } \\
0,14 \text { ha }\end{array}$ \\
\hline $29,2 \%$ & $30,6 \%$ & $\begin{array}{c}\text { Bertioga } \\
\text { (restinga seca alta) }\end{array}$ & $\begin{array}{c}\text { S.E. Martins et al. } \\
\text { (dados não publicados) }\end{array}$ & $\begin{array}{l}\text { Método de parcelas; altura } \\
\text { acima de } 2 \mathrm{~m} \text {; área amostral: } \\
0,03 \text { ha }\end{array}$ \\
\hline $14,3 \%$ & $12,3 \%$ & $\begin{array}{c}\text { Bertioga } \\
\text { (restinga seca baixa) }\end{array}$ & $\begin{array}{c}\text { S.E. Martins et al. } \\
\text { (dados não publicados) }\end{array}$ & $\begin{array}{l}\text { Método de parcelas; altura } \\
\text { acima de } 2 \mathrm{~m} \text {; área amostral: } \\
0,01 \text { ha }\end{array}$ \\
\hline $22,1 \%$ & $23,1 \%$ & $\begin{array}{c}\text { Picinguaba } \\
\text { (floresta sobre cordões) }\end{array}$ & Cesar \& Monteiro (1995) & $\begin{array}{l}\text { Método de parcelas; PAP } \\
\geq 15 \mathrm{~cm} \text {; área amostral: } 0,52 \text { ha }\end{array}$ \\
\hline $15,5 \%$ & $15,3 \%$ & $\begin{array}{l}\text { Picinguaba } \\
\text { (duna interior) }\end{array}$ & Assis (1999) & $\begin{array}{l}\text { Método de parcelas; PAP } \\
\geq 15 \mathrm{~cm} \text {; área amostral: } 0,1 \text { ha }\end{array}$ \\
\hline $14,6 \%$ & $21,2 \%$ & $\begin{array}{l}\text { Picinguaba } \\
\text { (cordões litorâneas) }\end{array}$ & Assis (1999) & $\begin{array}{l}\text { Método de parcelas; PAP } \\
\geq 15 \mathrm{~cm} \text {; área amostral: } 0,1 \text { ha }\end{array}$ \\
\hline $10,8 \%$ & $14,3 \%$ & $\begin{array}{l}\text { Picinguaba } \\
\text { (aluvionar) }\end{array}$ & Assis (1999) & $\begin{array}{l}\text { Método de parcelas; PAP } \\
\geq 15 \mathrm{~cm} \text {; área amostral: } 0,1 \text { ha }\end{array}$ \\
\hline $63,0 \%$ & - & área 2 & Este estudo & $\begin{array}{l}\text { Método de parcelas; PAP } \\
\geq 10 \mathrm{~cm} \text {; área amostral: 0,24 ha }\end{array}$ \\
\hline
\end{tabular}

pelo valor $\mathrm{m}$, que variou de 52 a $60 \%$ para a área $1 \mathrm{e}$ de 83 a $85 \%$ para a área 2 , mostrando a presença de solos álicos.

Por outro lado, embora não sofra regime de alagamento intenso, a área 2 tem fertilidade do solo ainda inferior a área 1 , sendo a atmosfera e a camada de solo dos primeiros $5 \mathrm{~cm}$ a maior fonte de nutrientes, que são rapidamente reabsorvidos por uma trama de sistemas subterrâneos (Hay \& Lacerda 1984).

Portanto, como descrito por Casagrande (2003), a floresta de restinga é mantida pela ciclagem de nutrientes, sendo a fitomassa a sua principal reserva. Tal constatação demonstra que a fragilidade desse ecossistema está relacionada à retirada da vegetação, que interrompe a adição de nutrientes e matéria orgânica e, expõe áreas a perdas por erosão e lixiviação.

No levantamento florístico realizado, observa-se que os resultados relacionados às principais famílias são bastante próximos, tanto entre as duas áreas deste estudo como entre estas e outros levantamentos de floresta de restinga no Estado de São Paulo (Ramos Neto 1993; Cesar \& Monteiro 1995; Carvalhaes 1997; Sugiyama 1998; Assis 1999; Sztutman \& Rodrigues 2002), sendo Myrtaceae a família mais característica deste tipo de formação, o que de acordo com Ashton (1988) deve-se a grande riqueza de espécies adaptadas às mais variadas condições ambientais.

Quanto à composição de espécies, nota-se que as áreas de estudo são muito semelhantes entre si, o que provavelmente deve-se mais à grande proximidade entre elas do que às condições de fertilidade de solo. Tal semelhança na composição florística torna difícil a distinção entre as duas florestas, que podem ser diferenciadas, basicamente, pelas condições de drenagem e de nutrientes do solo (Silva \& Britez 2005). 
Tabela 5. Parâmetros fitossociológicos das espécies amostradas na área 1 (floresta de restinga inundável), Município de Bertioga, SP, Brasil, ordenadas segundo o Valor de Importância (VI). Ni = Número de indivíduos; $\mathrm{Np}=$ Número de parcelas de ocorrência; $\mathrm{DR}=\mathrm{Densidade}$ Relativa; DoR = Dominância Relativa; FR= Freqüência relativa.

\begin{tabular}{|c|c|c|c|c|c|c|}
\hline Espécie & $\mathrm{Ni}$ & $\mathrm{Np}$ & DR & DoR & FR & VI \\
\hline Manilkara subsericea & 27 & 12 & 5,67 & 27,55 & 4,21 & 37,44 \\
\hline Amaioua intermedia & 81 & 22 & 17,02 & 12,15 & 7,72 & 36,89 \\
\hline Didymopanax angustissimum & 30 & 15 & 6,30 & 5,28 & 5,26 & 16,85 \\
\hline Miconia cubatanensis & 12 & 7 & 2,52 & 7,29 & 2,46 & 12,27 \\
\hline Euterpe edulis & 27 & 14 & 5,67 & 1,45 & 4,91 & 12,03 \\
\hline Syagrus pseudococos & 31 & 7 & 6,51 & 1,99 & 2,46 & 10,96 \\
\hline Bactris setosa & 21 & 14 & 4,41 & 1,19 & 4,91 & 10,52 \\
\hline Guarea macrophylla & 18 & 12 & 3,78 & 1,97 & 4,21 & 9,96 \\
\hline Nectandra oppositifolia & 11 & 9 & 2,31 & 4,25 & 3,16 & 9,71 \\
\hline Calophyllum brasiliense & 6 & 3 & 1,26 & 5,98 & 1,05 & 8,29 \\
\hline Eugenia stigmatosa & 10 & 7 & 2,10 & 2,97 & 2,46 & 7,53 \\
\hline Sloanea guianensis & 8 & 4 & 1,68 & 3,66 & 1,40 & 6,74 \\
\hline Ilex theezans & 12 & 9 & 2,52 & 0,85 & 3,16 & 6,53 \\
\hline Alchornea triplinervia & 10 & 8 & 2,10 & 0,91 & 2,81 & 5,81 \\
\hline Garcinia gardneriana & 9 & 9 & 1,89 & 0,62 & 3,16 & 5,67 \\
\hline Peraglabrata & 9 & 4 & 1,89 & 2,01 & 1,40 & 5,31 \\
\hline Tapirira guianensis & 8 & 5 & 1,68 & 1,48 & 1,75 & 4,92 \\
\hline Endlicheria paniculata & 8 & 7 & 1,68 & 0,72 & 2,46 & 4,86 \\
\hline Astrocaryum aculeatissimum & 8 & 7 & 1,68 & 0,42 & 2,46 & 4,55 \\
\hline Rudgea coriacea & 7 & 7 & 1,47 & 0,52 & 2,46 & 4,44 \\
\hline Posoqueria latifolia & 4 & 4 & 0,84 & 1,94 & 1,40 & 4,18 \\
\hline Eugenia sp.1 & 7 & 4 & 1,47 & 1,13 & 1,40 & 4,01 \\
\hline Myrcia acuminatissima & 7 & 5 & 1,47 & 0,65 & 1,75 & 3,87 \\
\hline Ilex amara & 6 & 4 & 1,26 & 1,08 & 1,40 & 3,74 \\
\hline Andira fraxinifolia & 6 & 5 & 1,26 & 0,61 & 1,75 & 3,63 \\
\hline Tabebuia obtusifolia & 7 & 4 & 1,47 & 0,67 & 1,40 & 3,55 \\
\hline Tabebuia cassinoides & 4 & 4 & 0,84 & 1,13 & 1,40 & 3,38 \\
\hline Miconia fasciculata & 5 & 5 & 1,05 & 0,24 & 1,75 & 3,04 \\
\hline Eugenia sulcata & 4 & 4 & 0,84 & 0,55 & 1,40 & 2,80 \\
\hline Gordonia fruticosa & 2 & 2 & 0,42 & 1,50 & 0,70 & 2,63 \\
\hline Eugenia riedeliana & 5 & 3 & 1,05 & 0,47 & 1,05 & 2,57 \\
\hline Cybianthus peruvianus & 4 & 4 & 0,84 & 0,17 & 1,40 & 2,42 \\
\hline Mollinedia schotiana & 4 & 4 & 0,84 & 0,13 & 1,40 & 2,37 \\
\hline Guatteria hillariana & 4 & 4 & 0,84 & 0,13 & 1,40 & 2,37 \\
\hline Guapira opposita & 4 & 3 & 0,84 & 0,29 & 1,05 & 2,18 \\
\hline Eugenia oblongata & 2 & 2 & 0,42 & 0,91 & 0,70 & 2,03 \\
\hline Maytenus robusta & 4 & 3 & 0,84 & 0,09 & 1,05 & 1,98 \\
\hline Nectandra sp. & 3 & 2 & 0,63 & 0,40 & 0,70 & 1,73 \\
\hline Cabralea canjerana & 3 & 2 & 0,63 & 0,18 & 0,70 & 1,51 \\
\hline Jacaranda puberula & 2 & 2 & 0,42 & 0,39 & 0,70 & 1,51 \\
\hline Eugenia neolanceolata & 2 & 2 & 0,42 & 0,34 & 0,70 & 1,46 \\
\hline Heisteria silvianii & 2 & 2 & 0,42 & 0,29 & 0,70 & 1,41 \\
\hline Eugenia monosperma & 2 & 1 & 0,42 & 0,64 & 0,35 & 1,41 \\
\hline Ficus luschnatiana & 2 & 2 & 0,42 & 0,22 & 0,70 & 1,35 \\
\hline Rapanea venosa & 2 & 2 & 0,42 & 0,22 & 0,70 & 1,34 \\
\hline Myrcia multiflora & 2 & 2 & 0,42 & 0,22 & 0,70 & 1,32 \\
\hline Myrcia grandiflora & 2 & 2 & 0,42 & 0,12 & 0,70 & 1,24 \\
\hline Eugenia umbelliflora & 2 & 1 & 0,42 & 0,46 & 0,35 & 1,24 \\
\hline Ocotea pulchella & 2 & 2 & 0,42 & 0,08 & 0,70 & 1,20 \\
\hline Ocotea lobbii & 2 & 2 & 0,42 & 0,05 & 0,70 & 0,17 \\
\hline Marlierea racemosa & 2 & 1 & 0,42 & 0,27 & 0,35 & 1,04 \\
\hline Myrtaceae sp.1 & 1 & 1 & 0,21 & 0,21 & 0,35 & 0,77 \\
\hline Myrcia fallax & 1 & 1 & 0,21 & 0,17 & 0,35 & 0,73 \\
\hline Psychotria cartagenensis & 1 & 1 & 0,21 & 0,17 & 0,35 & 0,73 \\
\hline
\end{tabular}


Tabela 5 (continuação)

\begin{tabular}{|c|c|c|c|c|c|c|}
\hline Espécie & $\mathrm{Ni}$ & $\mathrm{Np}$ & DR & DoR & FR & VI \\
\hline Dahlstedtia pinnata & 1 & 1 & 0,21 & 0,17 & 0,35 & 0,73 \\
\hline Miconia sellowiana & 1 & 1 & 0,21 & 0,13 & 0,35 & 0,69 \\
\hline Myrtaceae sp.2 & 1 & 1 & 0,21 & 0,07 & 0,35 & 0,63 \\
\hline Trichipteris atrovirens & 1 & 1 & 0,21 & 0,05 & 0,35 & 0,62 \\
\hline Ocotea sp. & 1 & 1 & 0,21 & 0,05 & 0,35 & 0,62 \\
\hline Abarema brachystachia & 1 & 1 & 0,21 & 0,05 & 0,35 & 0,61 \\
\hline Myrcia sp. & 1 & 1 & 0,21 & 0,04 & 0,35 & 0,60 \\
\hline Matayba junglandifolia & 1 & 1 & 0,21 & 0,03 & 0,35 & 0,59 \\
\hline Podocarpus sellowii & 1 & 1 & 0,21 & 0,02 & 0,35 & 0,58 \\
\hline Mollinedia oligantha & 1 & 1 & 0,21 & 0,02 & 0,35 & 0,58 \\
\hline Psychotria deflexa & 1 & 1 & 0,21 & 0,01 & 0,35 & 0,57 \\
\hline
\end{tabular}

Tabela 6. Parâmetros fitossociológicos das espécies amostradas na área 2 (floresta de restinga não inundável), Município de Bertioga, SP, Brasil, ordenadas segundo o Valor de Importância (VI). Ni = Número de indivíduos; $\mathrm{Np}=$ Número de parcelas de ocorrência; DR = Densidade Relativa; DoR = Dominância Relativa; FR = Freqüência Relativa.

\begin{tabular}{|c|c|c|c|c|c|c|}
\hline Espécie & $\mathrm{Ni}$ & $\mathrm{Np}$ & DR & DoR & FR & VI \\
\hline Eriotheca pentaphylla & 26 & 17 & 6,24 & 13,57 & 6,37 & 26,17 \\
\hline Calophyllum brasiliense & 9 & 6 & 2,16 & 13,73 & 2,25 & 18,13 \\
\hline Syagrus pseudococos & 28 & 16 & 6,71 & 4,06 & 5,99 & 16,77 \\
\hline Tabebuia cassinoides & 31 & 9 & 7,43 & 5,33 & 3,37 & 16,13 \\
\hline Manilkara subsericea & 10 & 7 & 2,40 & 10,93 & 2,62 & 15,95 \\
\hline Tabebuia obtusifolia & 23 & 12 & 5,52 & 2,35 & 4,49 & 12,36 \\
\hline Didymopanax angustissimum & 10 & 7 & 2,40 & 7,01 & 2,62 & 12,03 \\
\hline Sloanea guianensis & 17 & 10 & 4,08 & 2,48 & 3,75 & 10,30 \\
\hline Amaioua intermedia & 19 & 8 & 4,56 & 1,60 & 3,00 & 9,16 \\
\hline Guarea macrophylla & 16 & 11 & 3,84 & 1,14 & 4,12 & 9,10 \\
\hline Endlicheria paniculata & 14 & 10 & 3,36 & 1,92 & 3,75 & 9,02 \\
\hline Eugenia stigmatosa & 13 & 13 & 3,12 & 2,86 & 3,00 & 8,97 \\
\hline Garcinia gardneriana & 20 & 8 & 4,80 & 0,94 & 3,00 & 8,73 \\
\hline Jacaranda puberula & 12 & 8 & 2,88 & 2,40 & 3,00 & 8,28 \\
\hline Eugenia sulcata & 10 & 5 & 2,40 & 3,92 & 1,87 & 8,20 \\
\hline Guapira opposita & 8 & 5 & 1,92 & 3,20 & 1,87 & 6,99 \\
\hline Nectandra sp. & 8 & 5 & 1,92 & 2,20 & 1,87 & 5,99 \\
\hline Nectandra oppositifolia & 7 & 6 & 1,68 & 1,95 & 2,25 & 5,88 \\
\hline Rudgea coriacea & 9 & 8 & 2,16 & 0,28 & 3,00 & 5,43 \\
\hline Alchornea triplinervia & 9 & 7 & 2,16 & 0,37 & 2,62 & 5,15 \\
\hline Gordonia fruticosa & 2 & 2 & 0,48 & 3,28 & 0,75 & 4,51 \\
\hline Eugenia sp.1 & 8 & 5 & 1,92 & 0,51 & 1,87 & 4,30 \\
\hline Eugenia sp.2 & 8 & 4 & 1,44 & 0,69 & 1,50 & 4,11 \\
\hline Calyptranthes concinna & 6 & 3 & 0,96 & 0,76 & 1,12 & 3,32 \\
\hline Ocotea venulosa & 4 & 4 & 1,20 & 0,84 & 1,50 & 3,25 \\
\hline Eugenia monosperma & 5 & 3 & 0,72 & 0,93 & 1,12 & 3,08 \\
\hline Coussapoua microcarpa & 3 & 3 & 0,72 & 1,23 & 1,12 & 3,07 \\
\hline Eugenia neolanceolata & 4 & 4 & 1,20 & 0,17 & 1,50 & 2,87 \\
\hline Cupania oblongifolia & 4 & 4 & 0,96 & 0,27 & 1,50 & 2,73 \\
\hline Myrcia acuminatissima & 4 & 3 & 0,96 & 0,52 & 1,12 & 2,60 \\
\hline Miconia cubatanensis & 2 & 4 & 0,96 & 0,09 & 1,50 & 2,55 \\
\hline Ocotea sp. & 2 & 2 & 0,48 & 1,20 & 0,75 & 2,43 \\
\hline Myrcia multiflora & 4 & 3 & 0,96 & 0,27 & 1,12 & 2,36 \\
\hline Trichipteris atrovirens & 3 & 3 & 0,72 & 0,51 & 1,12 & 2,35 \\
\hline Inga edulis & 4 & 2 & 0,96 & 0,64 & 0,75 & 2,34 \\
\hline Guatteria hillariana & 3 & 3 & 0,72 & 0,29 & 1,12 & 2,13 \\
\hline Heisteria silvianii & 3 & 3 & 0,72 & 0,22 & 1,12 & 2,06 \\
\hline
\end{tabular}


Tabela 6 (continuação)

\begin{tabular}{|c|c|c|c|c|c|c|}
\hline Espécie & $\mathrm{Ni}$ & $\mathrm{Np}$ & DR & DoR & FR & VI \\
\hline Eugenia $\mathrm{cf}$. riedeliana & 3 & 2 & 0,72 & 0,46 & 0,75 & 1,93 \\
\hline Astrocaryum aculeatissimum & 3 & 2 & 0,72 & 0,25 & 0,75 & 1,72 \\
\hline Balizia pedicellaris & 2 & 2 & 0,48 & 0,42 & 0,75 & 1,65 \\
\hline Euterpe edulis & 3 & 2 & 0,72 & 0,17 & 0,75 & 1,64 \\
\hline Andira fraxinifolia & 2 & 2 & 0,48 & 0,34 & 0,75 & 1,56 \\
\hline Myrcia grandiflora & 2 & 2 & 0,24 & 0,29 & 0,37 & 1,52 \\
\hline Tapirira guianensis & 2 & 2 & 0,48 & 0,27 & 0,75 & 1,50 \\
\hline Rapanea venosa & 2 & 2 & 0,48 & 0,13 & 0,75 & 1,36 \\
\hline Ocotea aciphylla & 1 & 1 & 0,24 & 0,73 & 0,37 & 1,34 \\
\hline Ilex theezans & 2 & 2 & 0,48 & 0,05 & 0,75 & 1,28 \\
\hline Eugenia umbelliflora & 2 & 1 & 0,48 & 0,42 & 0,37 & 1,11 \\
\hline Cordia sellowiana & 2 & 1 & 0,48 & 0,26 & 0,37 & 1,01 \\
\hline Maytenus robusta & 2 & 1 & 0,48 & 0,16 & 0,37 & 0,95 \\
\hline Pera glabrata & 1 & 1 & 0,24 & 0,30 & 0,37 & 0,91 \\
\hline Cecropia glaziovii & 1 & 1 & 0,24 & 0,30 & 0,37 & 0,91 \\
\hline Myrcia tomentosa & 2 & 1 & 0,48 & 0,04 & 0,37 & 0,89 \\
\hline Aniba firmula & 1 & 1 & 0,24 & 0,23 & 0,37 & 0,85 \\
\hline Eugenia oblongata & 1 & 1 & 0,24 & 0,20 & 0,37 & 0,82 \\
\hline Myrciafallax & 1 & 1 & 0,24 & 0,16 & 0,37 & 0,77 \\
\hline Myrcia cf. brasiliensis & 1 & 1 & 0,24 & 0,14 & 0,37 & 0,75 \\
\hline Ocotea pulchella & 1 & 1 & 0,24 & 0,07 & 0,37 & 0,68 \\
\hline Bactris setosa & 1 & 1 & 0,24 & 0,05 & 0,37 & 0,67 \\
\hline Myrtaceae sp.2 & 1 & 1 & 0,24 & 0,05 & 0,37 & 0,66 \\
\hline Myrtaceae sp.1 & 1 & 1 & 0,24 & 0,05 & 0,37 & 0,66 \\
\hline Cabralea canjerana & 1 & 1 & 0,24 & 0,04 & 0,37 & 0,66 \\
\hline Psychotria cartagenensis & 1 & 1 & 0,24 & 0,04 & 0,37 & 0,65 \\
\hline Matayba junglandifolia & 1 & 1 & 0,24 & 0,02 & 0,37 & 0,63 \\
\hline Cybianthus peruvianus & 1 & 1 & 0,24 & 0,01 & 0,37 & 0,63 \\
\hline Eugenia handroana & 1 & 1 & 0,24 & 0,01 & 0,37 & 0,63 \\
\hline Hediosmum brasiliense & 1 & 1 & 0,24 & 0,01 & 0,37 & 0,63 \\
\hline
\end{tabular}

Algumas espécies típicas de ambientes alagados como Calophyllum brasiliense, Euterpe edulis e Tabebuia cassinoides (Mantovani 1992; Sztutman \& Rodrigues 2002), foram encontradas nas duas áreas de estudo, o que se deve ao caráter úmido da área $1 \mathrm{e}$ a presença de charcos de água entre a vegetação na área 2, sendo estes os principais locais onde tais espécies foram levantadas e, favorecendo assim as semelhanças florísticas ocorrentes entre as duas áreas.

Apesar de possuírem condições edáficas diferentes, as áreas estudadas podem ser consideradas muito semelhantes floristicamente, já que apresentam índice de similaridade bastante superior a 25\% (MüllerDombois \& Ellenberg 1974). Além disso, a composição florística das duas áreas foi caracterizada utilizando-se a mesma metodologia de levantamento, com o mesmo número de unidades amostrais e o mesmo critério de inclusão de indivíduos.

$\mathrm{Na}$ comparação florística realizada com outras áreas de floresta de restinga do Estado de São Paulo, observa-se que as maiores similaridades encontradas foram entre as áreas deste estudo e a área de Bertioga (restinga paludosa) estudada por S.M. Martins et al. (dados não publicados) o que, neste caso, pode mostrar que a proximidade geográfica foi um fator de grande importância na composição das espécies, já que a área 2 e Bertioga (restinga paludosa), com condições diferenciadas de solos e métodos fitossociológicos diferentes, apresentaram similaridade relativamente alta. Além disso, as áreas deste estudo apresentam-se muito mais impactadas do que as áreas de Bertioga estudadas por S.M. Martins et al. (dados não publicados), que se encontram bem preservadas e com maior proximidade da Serra do Mar.

Algumas áreas ao serem comparadas com as áreas do presente estudo apresentaram valores de similaridade muito baixos, o que pode estar relacionado a diferentes fatores, como as idades geológicas das restingas, sua proximidade com a encosta atlântica, grau de influência marinha, grau de inundação, distanciamento entre as áreas e à história de intervenção antrópica (Carvalhaes 1998). 
Entretanto, no geral, pode-se considerar que as áreas de estudo e as outras florestas comparadas mostraram alta similaridade, o que pode ser explicado pela ampla distribuição de espécies de restinga (Ramos Neto 1993), algumas como Andira fraxinifolia, Alchornea triplinervia, Ilex theezans, Pera glabrata e Guapira opposita são encontradas em quase todos os levantamentos, sendo Ilex theezans uma espécie característica de restinga e as outras muito encontradas também na Floresta Atlântica.

Desta forma, visto a taxa de similaridade que ocorre entre os dois trechos de mata deste estudo, pode-se dizer que a vegetação de restinga apresenta-se adaptada a mudanças bruscas de tipos de solo, regime hídrico e de luminosidade o que a torna, até um certo ponto, resistente a certas alterações antrópicas, causadas nas áreas de estudo pelos diversos arruamentos e pela presença da BR-101, que podem estar promovendo importantes modificações no fluxo de calor e de vento, perda de área e maior exposição ao efeito de borda, dentre outras conseqüências, favorecendo assim as semelhanças florísticas entre as duas áreas.

Em termos fitossociológicos, nota-se que as densidades totais encontradas para cada área podem ser consideradas baixas em relação as outras áreas com formações florestais semelhantes, cujos achados variam entre 2.858 ind./ha e 8.670 ind./ha (Silva 1990; Ramos Neto 1993; Sugiyama 1998; Fabris 1995; Fabris \& Cesar 1996). Já as áreas basais totais indicam valores altos, em comparação com os mesmos estudos, mostrando a ocorrência de uma relação contrária entre densidade e área basal, ou seja, uma menor densidade se refletindo numa maior área basal.

Entretanto, nos trabalhos realizados por Ramos Neto (1993), Silva (1998) e Sztutman \& Rodrigues (2002) foram adotados critérios de inclusão maiores do que $10 \mathrm{~cm}$ de PAP e encontradas densidades superiores as deste estudo, o que pode ser explicado pela presença freqüente de indivíduos bastante ramificados ou perfilhados ocupando extensa área nas florestas aqui estudadas, isso demonstra, como sugerido anteriormente por Assumpção \& Nascimento (2000), ser a rebrota um importante mecanismo de regeneração em áreas de restinga que sofrem ou sofreram algum tipo de perturbação.

Pela análise das Tabelas 5 e 6, referentes aos parâmetros fitossociológicos para as área 1 e 2, observa-se que as espécies presentes nas duas áreas apresentam semelhanças significativas em relação aos valores de freqüência, densidade e dominância, ocupando posições de VIs próximas.

Comparando as 10 primeiras colocadas em VI da área 1 com as da área 2, nota-se que seis são comuns às duas áreas (Manilkara subsericea, Amaioua intermedia, Didymopanax angustissimum, Syagrus pseudococos, Guarea macrophylla e Calophyllum brasiliense).

Manilkara subsericea foi a primeira colocada na área 1, enquanto na área 2 esta espécie ocupou a quinta posição, o que se deve a sua alta densidade aliada ao grande porte. Já Amaioua intermedia, apesar de possuir número de indivíduos muito superior a Manilkara subsericea, apresenta, por exibir um porte bem menos elevado, o segundo maior VI na área $1 \mathrm{e}$ nono na área 2.

Também devido a sua elevada dominância relativa e elevada densidade, Eriotheca pentaphylla aparece na área 2 com o maior VI, seguida por Calophyllum brasiliense e Tabebuia cassinoides, localizadas em charcos existentes nesta área.

Entretanto, apesar de Calophyllum brasiliense aparecer com um valor de importância mais elevado na área 2 do que na área 1, o número de indivíduos desta espécie em ambas as comunidades são bem próximos, o que indica que na área 2 o seu alto VI deve-se a uma elevada dominância, ou seja, poucos indivíduos com grande porte.

Desta forma, verifica-se que os maiores VIs, para as duas áreas, são das espécies com altas dominâncias, devido mais aos seus portes elevados do que a altas densidades.

Já os índices de Shannon (H') foram significativamente diferentes nas duas áreas (teste $t$ de Hutcheson) e a mesma tendência pode ser observada para a equiabilidade, sendo este índice o principal responsável pela diferença encontrada para H', já que a riqueza em espécies é muito semelhante entre as duas áreas. Segundo Ashton (1990), uma concentração de abundâncias em algumas espécies é mais pronunciada em solos mal drenados e com maior fertilidade, como é o caso da área 1 que apresenta aproximadamente $17 \%$ de seus indivíduos pertencente a espécie Amaioua intermedia.

Assim, de forma geral, e considerando que o índice de diversidade é apenas um dos vários parâmetros utilizados neste estudo, pode-se concluir que as duas áreas são floristica e estruturalmente bastante semelhantes, já que apresentam características muito parecidas tais como composição de espécies, densidade total de indivíduos, área basal total e posições das espécies em relação ao VI. 
Estas semelhanças, no entanto, podem ser devidas ao fato das duas áreas estarem sujeitas às mesmas condições de influência antrópica; apresentarem praticamente o mesmo tamanho; encontrarem-se próximas, estando sujeitas às mesmas condições climáticas e fontes de propágulos; e apresentarem espécies adaptadas às mais variadas condições ambientais, o que estabelece a ocorrência simultânea de algumas populações com valores de freqüência, dominância e densidade próximos.

\section{Agradecimentos}

Os autores agradecem ao $\mathrm{CNPq}$, pela bolsa concedida à primeira autora; aos pesquisadores da UNESP, Instituto de Botânica de São Paulo e Instituto Florestal que colaboraram na identificação do material botânico; a Marcos Sobral da Universidade Federal de Minas Gerais, pela identificação das Myrtaceae.

\section{Referências bibliográficas}

Andrade, M.A.B. \& Lamberti, A. 1965. A Baixada Santista. Aspectos geográficos. As bases físicas. São Paulo, Editora da Universidade de São Paulo.

Araújo, D.S.D. 1992. Vegetations types of sandy coastal plains of tropical Brazil: a first aproximation. Pp. 337-347. In: U. Seeliger (coord.). Coastal plant communities of latin America. New York, Academic Press.

Araújo, D.S.D. \& Henriques, R.P.B. 1984. Análise florística das restingas do Estado do Rio de Janeiro. Pp. 159-193. In: L.D. Lacerda. Restingas: origem, estrutura e processos. Niterói, CEUFF.

Araújo, D.S.P. \& Lacerda, R.P.B. 1987. Natureza das restingas. Ciência Hoje 6: 42-48.

Ashton, P.S. 1988. Systematics and ecology of rain forest trees. Taxon 37(3): 633-629.

Ashton, P.S. 1990. Species richness in tropical forests. Pp. 239-251. In: L.B. Holm-Nielsen; I.C. Nielsen \& H. Balslev (eds.). Tropical Forests - botanical dynamics, speciation and diversity. London, Academic Press.

Assis, M.A. 1999. Florística e caracterização das comunidades vegetais da Planície Costeira de Pinciguaba, Ubatuba-SP. Tese de Doutorado. Campinas, Universidade Estadual de Campinas.

Assumpção, J. \& Nascimento, M.T. 2000. Estrutura e composição florística de quatro formações vegetais de restinga no complexo lagunar Grussaí/Iquipari, São João da Barra, RJ, Brasil. Acta Botanica Brasilica 14(3): 301-315.

Barros, F.; Melo, M.M.R.F.; Chiea, S.A.C.; Kirizawa, M.; Wanderley, M.G.L. \& Jung-Mendaçolli, S.L. 1991. Caracterização geral da vegetação e listagem das espécies ocorrentes. Flora Fanerogâmica da Ilha do Cardoso 1: 1-184.
Carvalhaes, M.A. 1997. Florística e estrutura de mata sobre restinga na Juréia, Iguape, SP. Dissertação de Mestrado. São Paulo, Universidade de São Paulo.

Casagrande, J.C. 2003. Considerações sobre recuperação da fertilidade do solo para áreas degradadas. Pp. 92-93. In: Anais do Seminário temático sobre recuperação de áreas degradadas. São Paulo, FAPESP IBt/SMA.

Cesar, O. \& Monteiro, R. 1995. Florística e fitossociologia de uma Floresta de Restinga em Picinguaba (Parque Estadual da Serra do Mar), Município de Ubatuba-SP. Naturalia 20: 89-105.

Conama. 1996. Conselho Nacional do Meio Ambiente. Anexo. Resolução n.7.

Consórcio Mata Atlântica. 1992. Reserva da Biosfera da Mata Atlântica. Plano de Ação. Campinas, UNICAMP.

De Grande, D.A. \& Lopes, E.A. 1981. Plantas da restinga da Ilha do Cardoso (São Paulo, Brasil). Hoehnea 9: 1-22.

Fierz, M.S.S. \& Rosa, F.S. 1999. A paisagem X evolução do uso e ocupação do solo em Bertioga, Litoral Paulista. Revista do Departamento de Geografia 13: 259-287.

Fabris, L.C. \& Cesar, O. 1996. Estudos florísticos em uma mata litorânea no Sul do Estado do Espírito Santo, Brasil. Boletim do Museu de Biologia Mello Leitão 5: 15-46.

Furlan, A.; Monteiro, R.; Cesar, O. \& Timoni, J.L. 1990. Estudos florísricos das matas de restinga de Picinguaba, SP. Pp. 220-227. In: $2^{\mathbf{0}}$ Simpósio de Ecossistemas da Costa Sul e Sudeste Brasileira: estrutura, função e manejo. Águas de Lindóia.

Garcia, F.C.P. \& Monteiro, R. 1993. Espécies de Leguminosae na planície litorânea arenosa em Picinguaba, UbatubaSP. Pp. 107-114. In: $3^{\circ}$ Simpósio de Ecossistemas da Costa Brasileira: subsídio a um gerenciamento ambiental. Serra Negra.

Girardi, A.C.S. 2001. Subsídios metodológicos para o planejamento e gestão de restingas estudo de caso Bertioga-SP. Dissertação de Mestrado. São Paulo, Universidade de São Paulo.

Hay, J.D. \& Lacerda, L.D. 1984. Ciclagem de nutrientes no ecossistema de restinga. Pp. 351-354. In: L.D. Lacerda (coord.). Simpósio sobre restingas. Restingas: origem, estrutura e processsos. Niterói, CEUFF.

Henriques, R.P.B.; Araújo, S.D. \& Hay, J.D. 1986. Descrição e classificação dos tipos de vegetação de restinga de Carapebus, Rio de janeiro. Revista Brasileira de Botânica 9: 173-189.

IPT. 1981. Prospecção regional de turfa no Estado de São Paulo. Relatório IPT, 15358.

Klein, R.M. 1961. Aspectos fitofisionômicos da Mata Pluvial da Costa Atlântica do sul do Brasil. Boletim da Sociedade Argentina de Botânica 9: 121-140.

Jordan, C.F. 1985. Nutrient cycling in tropical forest ecossystems. Chicherster, John Wiley \& Sons.

Kirizawa, M.; Lopes, E.A.; Pinto, M.M.; Lam, M. \& Lopes, M.I.M.S. 1992. Vegetação da Ilha Comprida: aspectos fisionômicos e florísticos. Pp. 386-391. In: $2^{\circ}$ Congresso Nacional sobre Essências Nativas. São Paulo, Instituto Florestal.

Köppen, W. 1948. Climatologia. Fondo de Cultura Econômica, México. 
Magurran, A.E. 1988. Ecological diversity and its measurement. London, Cambridge University.

Mantovani, W. 1992. A vegetação sobre a restinga de Caraguatatuba, SP. Pp.139-144. In: $2^{\circ}$ Congresso Nacional sobre Essências Nativas. v.4. São Paulo, Instituto Florestal.

Mantovani, W. 2000. A região litorânea paulista. Pp. 33-41. In: L.M. Barbosa (coord.). Anais do Workshop sobre recuperação de áreas degradadas da Serra do Mar e formações florestais litorâneas. São Paulo, Secretaria do Meio Ambiente.

Marques, M.M.C. 2002. Dinâmica da dispersão de sementes e regeneração de plantas da planície litorânea da Ilha do Mel, PR. Tese de Doutorado. Campinas, Universidade Estadual de Campinas.

Medeiros, V.B. 1965. Bertioga. Pp. 125-137. In: A. Azevedo. Baixada Santista, aspectos geográficos. São Paulo, Edusp.

Moraes, R.M.; Delitti, W.B.C. \& Struffaldi-De-Vuono, Y. 1999. Litter fall and litter nureant content two Brazilian Tropical Forest. Revista Brasileira de Botânica 50: 163-173.

Mohr, E.C.J. \& Van Baren, F.A. 1959. Tropical soils. A critical study of soil genesis as related to climate, rock and vegetation. New York, Interscience Publishers.

Müller-Dombois, D. \& Ellenberg, H. 1974. Aims and methods of vegetation ecology. New York, Willey and Sons.

Pereira, O.J. 1990. Caracterização fitofisionômica da restinga de Setiba, Guarapari, Espírito Santo. ACIESP 71(3): 207-219.

Pielou, E.C. 1975. Ecological diversity. New York, John Wiley.

Raij, B.V. \& Quaggio, J.A. 1983. Métodos de análise de solos para fins de fertilidade. Instituto Agronômico de Campinas. Boletim Técnico 81.

Raij, B.V. \& Zullo, M.A.T. 1977. Métodos de análise de solos. Instituto Agronômico de Campinas. Circular 63.

Ramos Neto, M.B.R. 1993. Análise florística e estrutural de duas florestas sobre a restinga, Iguape, SP. Dissertação de Mestrado. São Paulo, Universidade de São Paulo.

Ribeiro, J.E.L.S. \& Monteiro, R. 1993. Diversidade das orquídeas (Orchidaceae) da planície litorânea da Praia da Fazenda (Vila de Pinciguaba, Município de Ubatuba, SP) e ocorrência no litoral brasileiro. Pp. 99-106. In: $3^{\circ}$ Simpósio de Ecossistemas da Costa Brasileira: subsídio a um gerenciamento ambiental. Serra Negra.
Rodrigues, R.R. 2000. Recuperação de áreas degradadas em restinga. Pp.98-105. In: L.M. Barbosa (coord.). Anais do Workshop sobre recuperação de áreas degradadas da Serra do Mar e formações florestais litorâneas. São Paulo, Secretaria do Meio Ambiente.

Romero, R. \& Monteiro, R. 1993. Ocorrência da família Melastomataceae na planície litorânea de Picinguaba, município de Ubatuba, São Paulo. Pp.115-123. In: $3^{\circ}$ Simpósio de Ecossistemas da Costa Brasileira: subsídio a um gerenciamento ambiental. Serra Negra.

Shepherd, G.J. 1994. Fitopac-2. Manual do usuário. Campinas, Departamento de Botânica, UNICAMP.

Silva, S.M. 1990. Composição florística e fitossociológica de um trecho de restinga na Ilha do Mel, município de Paranaguá, PR. Dissertação de Mestrado. Campinas, Universidade Estadual de Campinas.

Silva, S.M. \& Britez, R.M. 2005. A vegetação da Planície Costeira. In: M.C.M. Marques \& R.M. Britez (orgs.). História natural e conservação da Ilha do Mel. Curitiba, Editora UFPR.

Silva, I.X.; Moraes, R.P.; Santos, R.P.; Pompéia, S.L. \& Martins, S.E. 1993. A degradação dos ecossistemas da Baixada Santista, São Paulo. Pp. 129-40. In: III Simpósio de Ecossistemas da Costa Brasileira. Serra Negra, ACIESP.

Sugiyama, M. 1998. Estudo de Florestas da Restinga da Ilha do Cardoso, Cananéia, São Paulo, Brasil. Boletim do Instituto de Botânica 11: 119-159.

Sztutman, M. \& Rodrigues, R.R. 2002. O mosaico vegetacional numa área de floresta contínua da planície litorânea, Parque Estadual de Campina do Encantado, Pariquera-Açu, SP. Revista Brasileira de Botânica 25(2): 161-176.

Troppmair, H. 1975. Regiões ecológicas do Estado de São Paulo. Biogeografia 10: 1-24.

Veloso, H.P.; Rangel Filho, A.L.R. \& Lima, J.C. 1991. Classificação da vegetação brasileira, adaptada a um sistema universal. Rio de Janeiro, IBGE, Departamento de Recursos Naturais e Estudos Ambientais.

Zar, J.H. 1996. Biostatistical analysis. $3^{\text {rd }}$ ed. New Jersey, Prentice-Hall Editions.

Waechter, J.L. 1986. Comunidades vegetais das restingas do Rio Grande do Sul. ACIESP 71(3): 228-248. 